\title{
Social Distance and Knowledge Transformation: The Effects of Social Network Distance on Organizational Learning
}

\author{
Brandy Aven, Evelyn Ying Zhang
}

Carnegie Mellon University

Abstract: Organizations are increasingly adopting technologies to promote knowledge sharing across boundaries of specialized groups. Yet, prior research beginning with March (1991) suggests that such knowledge-sharing technologies actually inhibit organizational learning by reducing solution diversity. This line of reasoning stems from the prior literature's assumption that the knowledge shared will be transferred from one member to another perfectly and without distortion. We challenge this assumption and argue, instead, that knowledge is often altered or transformed when it is shared between members and that the degree of this transformation increases as the social distance between the knowledge sender and receiver increases. Because the implementation of knowledge-sharing technologies encourages learning between members across greater social distances, it increases knowledge transformation. Thus, knowledge-sharing technologies present a new opportunity to diversify solutions and lead to innovation.

Keywords: organizational learning; knowledge transfer; knowledge transformation; social distance

Citation: Aven, Brandy, and Evelyn Ying Zhang. 2016. "Social Distance and Knowledge Transformation: The Effects of Social Network Distance on Organizational Learning." Sociological Science 3: 1103-1131.

Received: Septmeber 8, 2016

Accepted: October 28, 2016

Published: December 15, 2016

Editor(s): Jesper Sørensen, Olav Sorenson

DOI: $10.15195 / \mathrm{v} 3 . a 48$

Copyright: (C) 2016 The Author(s). This open-access article has been published under a Creative Commons Attribution License, which allows unrestricted use, distribution and reproduction, in any form, as long as the original author and source have been credited. @()
$\mathrm{O}$ RGANIZATIONS are increasingly adopting knowledge-sharing technologies to promote internal knowledge sharing amongst employees and help them identify experts. The intention of these knowledge-sharing technologies, such as knowledge management systems, solution documentation systems, and expertise directories, is to both democratize the access to internal knowledge and expedite the dissemination of solutions amongst organization members (Haas and Hansen 2007; Levine and Prietula 2012). In the absence of such technologies, members must rely on word of mouth to search for an expert or a solution, which is both difficult and time consuming (Levinthal and March 1993). In addition, a circumstance in which employees must query their social connections for expertise or solutions perpetuates unequal access to knowledge within the organization (Singh, Hansen, and Podolny 2010; Sorenson, Rivkin, and Flemming 2006). By making public to the organizational members both the experts and the potential solutions, knowledge-sharing technologies would appear to address these twin challenges of organizational learning and, in turn, should boost the organization's performance. Yet, simulation research on organizational learning beginning with March's (1991) seminal work suggests that these technologies instead reduce the organization's overall performance.

March (1991) argued that greater solution diversity coupled with the slow diffusion of solutions among members increases the likelihood that an organization will identify the optimal solution. Although often difficult to accomplish, discovering the optimal solution improves the organization's overall performance by 
providing an increased competitive advantage, such as an accurate knowledge of the environment (March 1991) or the ability to develop innovative products and services (Lazer and Friedman 2007). A key assumption of March's (1991) model and subsequent research is that the solutions are transferred perfectly and without distortion between members. When solutions take a long time to reach individual members, it encourages members to continue to iterate on the problem through experimentation, and, in turn, increases the likelihood that the organization will discover the optimal solution. By contrast, rapid diffusion of solutions leads to solution homogeneity, and, consequently, the organization prematurely converges on a suboptimal solution. For example, consider two organizational scenarios in which the members are collectively trying to solve a problem, such as creating nonpolluting fuel. In both scenarios, one member, $A$, happens to discover a solution that is slightly better than all the other members' but is the not the optimal solution to the problem. In the first scenario, in which there is rapid diffusion, the socially proximate neighbors to $A$ quickly adopt $A^{\prime}$ 's solution because it is better than their own solutions. Next, the neighbors of $A^{\prime}$ 's neighbors also adopt the same solution because it outperforms their solutions as well. With this rapid diffusion, all the members ultimately have the same solution. Once everyone shares the same solution, the members assume that the optimal solution has been discovered and that there is no reason to continue to experiment or search for improvements. Alternatively, in another scenario in which diffusion is slow, it is far less likely that the organization will be quickly overrun with member $A$ 's solution. As $A$ 's solution diffuses in this scenario, members have more time to continue to experiment, which increases the odds that the members will discover the optimal solution. Hence, subsequent work argues that various factors that delay diffusion of solution result in the greater solution diversity necessary for organizational members to discover, or at least approach, the optimal solution (Levinthal and March 1993). For instance, organizational learning improves when the communication network is structured into semi-isolated groups and limits the number of diffusion pathways (Fang, Lee, and Schilling 2010; Lazer and Friedman 2007). Together, this work suggests that efforts to accelerate knowledge diffusion within an organization often are counterproductive for organizational learning and innovation. Yet, these earlier studies assume complete transmission fidelity of solutions or perfect knowledge transfer between organizational members and assume that the only means to achieve solution diversity is through individual members' experimentation. Given these assumptions, the introduction of knowledge-sharing technologies would consequently accelerate diffusion and reduce solution diversity because members could easily find and copy other members' better solutions.

We challenge the assumption of perfect knowledge transfer. In particular, we contend that, as the knowledge sender and receiver are separated by greater social distance, the degree to which the knowledge will be transformed increases as well. Here, we define knowledge transformation as the intentional or unintentional modification of the original solution, which may or may not be an improvement. We base our argument on the overwhelming finding in the knowledge transfer literature that the process through which one organizational member learns from another member is fraught with challenges (Argote and Ingram 2000). In particular, these 
studies find that group boundaries, such as domain specialization or functional expertise, impede members from successfully transferring knowledge (Hansen 1999; Tortoriello, Reagans, and McEvily 2012). Carlile (2002) and Bechky (2003) both observe that it is largely the social differences between members of disparate groups that underlie the difficulties of knowledge transfer and that, in order for learning to occur between such members, knowledge must instead be transformed. Hence, because a greater social distance implies greater social differences between members, it also implies a greater likelihood that the knowledge will be transformed. By reducing search costs, knowledge-sharing technologies expand a member's search to include socially distant members and, thus, increase the likelihood that a solution will be transformed in the process. In this way, knowledge-sharing technologies, rather than reducing solution diversity and minimizing performance, can instead benefit organizations by introducing another source of solution heterogeneity to the system.

We examine the relationship between organizational learning and social distance using agent-based simulations in three computational experiments that reflect three distinct organizational scenarios. Investigating the effect of social network distance on organizational learning is particularly challenging, because real-world organizations rarely present opportunities to disentangle the influence of social distance from a host of other confounding variables such as organization size, network structure, density, and member characteristics. To address this challenge, we extend Fang et al.'s (2010) model, which is based on March's (1991) work, by modeling organizational learning as a function of social network distance between members. In our computational model, the likelihood of knowledge transfer decreases as the social network distance increases between members; however, when knowledge is shared across a greater social network distance, it is more likely to be transformed. In the first experiment, members can search for solutions only via their social network contacts, which is akin to how most learning transpires in organizations (Hansen 1999; Reagans and McEvily 2003; Tortoriello et al. 2012). In the second experiment, we allow members to search for experts across the entire organization via a public repository. Such public repositories, which convey who are the experts to an organization's members, such as knowledge management technologies, are becoming increasingly common in organizations (Haas and Hansen 2007; Hwang, Singh, and Argote 2015). The final experiment is a combination of the first two, in which members can learn both from experts in their social network and from the public repository. To measure organizational performance, we use two key outcomes highlighted by research on organizational learning: the efficiency of finding a solution (Hansen 1999; Levine and Prietula 2012) and effectiveness of the solution (Haas and Hansen 2007; Lazer and Friedman 2007).

The main contribution of this work is twofold. First, our work offers a novel perspective on organizational learning. Despite the growing simulation work on organizational learning, these models assume homogeneous and perfect knowledge transfer processes, whereas the knowledge transfer literature suggests a number of social impediments to perfect transfer. To our knowledge, we are the first to incorporate the concept of knowledge transformation into organizational learning models and show how this change reverses the predictions of earlier models. By 
allowing for the transformation of solutions via social distance, our model suggests that technologies and practices that promote diffusion amongst socially distant members may promote heterogeneous solutions rather than reducing them. Second, we provide a theoretical model linking social network distance to knowledge transformation and innovation. Although several studies suggest that bridging disparate social boundaries increases innovation (Burt 2004), we specify that one underlying mechanism is knowledge transformation. When members bridge groups, they are more likely to learn from socially distant others, which increases the likelihood that their solutions will be transformed, creating greater opportunities for innovation.

\section{Organizational Learning and Social Distance}

Organizational knowledge tends to be partitioned by group boundaries, such as functional areas or domain expertise (Bechky 2003; Dougherty 1992). Within these organizational groups, members commonly share similar knowledge, but across these groups, knowledge tends to differ (Burt 2004). In addition to knowledge differences, varied languages and mental models also separate groups and hinder their ability to communicate and share knowledge effectively (Bechky 2003; Carlile 2002; Dougherty 1992). Moreover, members of disparate groups are also less likely to trust one another, which, in turn, reduces their motivation to cooperate and share information (Szulanski 1996; Szulanski, Cappetta, and Jensen 2004). And in the rare cases when different groups do share connections, the connections are generally weak and can only transfer simple, codified knowledge as opposed to complex, tacit knowledge (Hansen 1999). Taken together, group boundaries pose a challenge for organizational learning within organizations.

But group boundaries are not simply discrete barriers between collections of homophilous organizational members. Instead, members are more or less similar to one another on an array of sociodemographic factors (Blau 1977; McPherson 2004). Importantly, members' sociodemographic factors, Blau (1977) argued, are largely reflected in their relationships-individuals who are homophilous are far more likely to be socially proximate, whereas individuals who are heterophilous are likely to be socially distant (McPherson 2004). Developing this argument, McPherson and Ranger-Moore (1991) proposed that social distance could be understood from a social network perspective. They argued that individuals who share attributes, such as education, occupation, language, and knowledge, are more likely to have a social tie or be socially proximate. In contrast, a pair of individuals with little to no common characteristics will not only not share a social tie but also be separated by many other individuals.

Within organizations, specialization and the division of labor also greatly exacerbate the social distance among members. Unsurprisingly, the social distance of members is strongly influenced by the organization's formal structure, such as its functional departments, its hierarchy, and its geography (Kleinbaum, Stuart, and Tushman 2013). Although it is often critical for different functional departments within an organization to coordinate with one another on products or for geographically dispersed members to share information, organizational members tend to share information only within their groups rather than across them (Hansen 
1999; Reagans and McEvily 2003). Therefore, learning amongst different groups is stymied.

One means of learning or identifying an expert is to search amongst socially proximate others or amongst direct connections in the social network (e.g., Lazer and Friedman 2007; Hansen 1999). Direct connections between organizational members can provide members with relevant knowledge about each other's expertise, which facilitates knowledge sharing (Borgatti and Cross 2003). Proximity in the social network also enhances interpersonal learning, because when individuals share a common understanding such as jargon or mutual meanings they are much more likely to be able to apprehend each other's solutions (Bechky 2003). In addition, knowledge sources are more likely to share knowledge with members who are proximate, such as those with whom they are directly connected or with whom they have a third party in common (Reagans and McEvily 2003; Tortoriello et al. 2012). By contrast, the lack of shared mental models that coincides with social network distance hinders the ability to communicate knowledge effectively (Dougherty 1992). Greater social distance can also undermine motivation, both for the sender's willingness to share knowledge and the receiver's willingness to try to comprehend the knowledge (Levinthal and March 1993; Szulanski 1996), and members can learn only if the other members are willing to transfer knowledge (Borgatti and Cross 2003; Hansen 1999). Lack of a common mental model, language, or goal hampers the ability of the knowledge source and recipient to transfer knowledge accurately (Bechky 2003). Moreover, organizational members often have different understandings of the same situation, as well as different interpretive schemas (Tortoriello, Taube, and Moebus 2014). As recipients attempt to learn solutions from distant sources, they might not fully comprehend all of the subtleties and implied meanings therein (Winter et al. 2012). In sum, learning via social networks facilitates local knowledge transfer but hinders knowledge transfer across large social network distances.

Paradoxically, when members search for solutions amongst those closest to them in the social network, their neighbors' solutions are less likely to be different from their own. And, unfortunately, organizational members' proximate contacts are not necessarily the experts who are best suited to help them (Miller, Zhao, and Calantone 2006). Levinthal and March (1993) argued that interpersonal learning commonly suffers from "spatial myopia," in which members learn predominantly from proximate others while ignoring distant alternatives. A search for an expert often begins with social network contacts because they are less costly to contact (Cyert and March, 1963). The search for expertise or knowledge, then, is heavily biased towards local connections. In addition, a circumstance in which employees must query their social connections for expertise or solutions perpetuates unequal access to knowledge within the organization (Singh et al. 2010; Sorenson et al. 2006). Thus, learning via the social network facilitates only incremental improvements to solutions and knowledge. 


\section{Knowledge Transformation}

We argue that, when the challenges of large social network distances for knowledge transfer are overcome, knowledge is more likely to be transformed and can lead to innovation. Carlile (2002) found that the languages and schemas of specialized groups necessitated that knowledge be augmented for it to be successfully transferred. In other words, knowledge sources may have to adjust their language about a product in order to communicate effectively, and recipients may need to change their conceptualization of that product. Bechky (2003) also observed that misunderstandings commonly occurred when engineers, technicians, and assemblers attempted to share information across their functional groups; however, once they were able to transform their knowledge, they could overcome miscommunications. Assuming that greater social network distance reflects greater differences amongst organizational members, we argue that the likelihood of knowledge transformation increases as the social network distance between the source and recipient increases.

By transforming knowledge across groups, organizational members create opportunities for innovation (Burt 2004; Hargadon and Sutton 1997; Lingo and O'Mahoney 2010; Obstfeld 2005). Specifically, when members in different groups or departments share mental models or schemas, they promote the knowledge sharing necessary for innovation (Dougherty 1992). Members who connect across different groups are better able to recognize alternative solutions and unidentified innovations (Burt 2004; Hargadon and Sutton 1997). Creative innovations are also produced when members engage in "nexus work," in which they integrate and synthesize the knowledge of distinct groups (Lingo and O'Mahoney 2010). Moreover, members who forge connections between socially distant others foster creativity and innovation development (Obstfeld 2005). Finally, learning from socially distant sources allows recipients to infuse novel insights and information to solve problems in a more innovative way (Bechky 2003; Carlile 2002). Therefore, the knowledge transformations brought about by learning across great social network distances are more likely to foster innovations.

\section{Promoting Learning among Socially Distant Members}

Attempting to overcome unequal access to knowledge and promote knowledge transfer among socially distant members, organizations are increasingly adopting knowledge-sharing technologies such as public knowledge repositories (Kane and Alavi 2007; Levine and Prietula 2012). Access to these public knowledge repositories permits organizational members to immediately identify experts and has been found to expand search processes beyond social network contacts (Kane and Alavi 2007; Levine and Prietula 2012). Organizations expect that, by overcoming the knowledge barriers between members, public knowledge repositories help members find socially distant sources of knowledge and obtain knowledge that was previously unknown to them. Yet, theories of learning and knowledge transfer suggest that, although these technologies reduce the clustering of information into silos and promote quick diffusion of solutions throughout the organization, they 
may undermine innovation (March 1991; Fang et al. 2010; Lazer and Friedman 2007; Schilling and Fang 2014).

As highlighted by March's (1991) work on organizational learning, organizational innovation is highly contingent on how quickly and easily a solution spreads among members. The rapid diffusion of an adequate solution among organizational members often inhibits the members from discovering a superior solution (March 1991; Fang et al. 2010; Lazer and Friedman 2007; Schilling and Fang 2014). For example, Lazer and Friedman (2007) showed that highly connected networks quickly diffuse and converge on suboptimal solutions. Similarly, Fang et al. (2010) showed that a highly efficient communication structure decreases the knowledge diversity in an organization, which impedes the organization's ability to discover or even approach the best solution (Schilling and Fang 2014). Furthermore, knowledge diversity has been cited as crucial to the success of an organization (Fleming, Mingo, and Chen 2007; Rodan and Galunic 2004). By assuming perfect knowledge transfer even between two very socially distant members, these prior studies argue that any factors that increase diffusion will also thereby extinguish knowledge diversity and the possibility of discovering the optimal solution (March 1991; Fang et al. 2010; Lazer and Friedman 2007). We argue instead that, when organizations encourage knowledge transfer over greater social network distances, they actually increase the diversity of organizational knowledge.

\section{Computational Model}

In computational models, a collective of simulated agents attempts to solve the same problem (e.g., Schilling and Fang 2014; Lazer and Friedman 2007). And, like actual members in real-world organizations, agents can either acquire solutions from others or develop novel solutions independently (e.g., March 1991). We use the NK model, which is commonly used to represent complex problems numerically, as the problem agents must solve (Levinthal 1997). The NK model is named after the two parameters that generate the problem spaces. $\mathrm{N}$ can be viewed as the number of knowledge dimensions in the solution array, whereas $\mathrm{K}$ is the level of dependence among those dimensions. In other words, in the NK model, the complexity of a problem arises not only from the number of elements it involves $(N)$ but also from the interdependence of the elements $(K)$. For example, if $(\mathrm{N}, \mathrm{K})=$ $(4,2)$, four digits comprise the entire solution, and each digit value is contingent on two other digits in the solution. Therefore, before the performance benefits of a one-digit improvement can be realized, the correct combination of two other digits must be satisfied. The NK models share several similarities with March's (1991) original organizational learning model. In particular, the parameter $N$ is analogous to the total number of beliefs in March's model.

Our simulation model is based on the following five key features:

1. All agents work on the same NK problem throughout a given simulation. There is an optimal solution to the complex problem that is independent of any agent's knowledge. The problem is modeled as an $\mathrm{N}$-dimensional vector, each digit of which has a value of either 1 or 0 . Each of the $n$ agents has her 
own solution to the problem. Initially, $n$ agents are assigned values of 1 or 0 for each digit on a random basis with independent equal probability. At each round of simulation, as with earlier work, agents can either exploit others' solutions (learn) or explore by working independently on the problem.

2. Agents are connected with one another by predetermined social network structures. Agents attempt to exploit the organizational knowledge base by learning from others' solutions. We construct three organizational scenarios that reflect different but common organizational learning conditions. Detailed specifications are explained in the subsequent subsection.

3. Each agent attempts to explore independently by randomly flipping one digit of her solution until she improves her performance score. If an improvement is found, the agent will stop experimentation for that round. She can try to flip digits in her solution $N$ times in one attempt to solve the problem before an improvement is reached ( $N$ is the total number of digits in a solution, as the " $N$ " in the NK problem).

4. We assume "conservative update" for agents in both exploration and exploitation, according to which they retain their best-performing solution (Lazer and Friedman 2007; Fang et al. 2010; Fang, Kim, and Milliken 2014). That is, agents will return to their previous best solution if their recent updates do not yield improved performance. In this way, agents' solutions do not regress but can only improve over time. An agent's updated solution can then be shared with other members in subsequent rounds.

5. An agent's decision to exploit or explore is based on her previous outcomes. We applied the "strategic persistence" assumption to agents; positive outcomes lead agents to continue with their current strategy, whereas negative outcomes trigger a strategy change (Fang et al. 2014). For instance, if an agent seeking solutions from others is successful, she will continue to seek solutions in the following period. Otherwise, if she does not acquire a better solution, she will switch to solving the problem independently.

Our key contribution involves differentiating knowledge transfer and knowledge transformation in our model by accounting for social distance between any two agents. Knowledge transfer will occur only if the expert is willing to share her solution (Borgatti and Cross 2003; Hansen 1999). Individuals are more likely to share their solutions with those who are proximate in the social network (Hansen 1999). Therefore, we assume that the likelihood of an agent sharing a solution with another agent is a function of her network distance from the other agent. Because a direct connection or sharing a third-party connection to another greatly increases the motivation to transfer knowledge (Reagans and McEvily 2003; Tortoriello et al. 2012), we assume transfers will be far more likely when network distance is less than or equal to two. Every agent's willingness to transfer a solution to another, given a particular network distance, is randomly sampled from a normal distribution. We assume that the likelihood of knowledge transfer between two agents is a normal distributed $N(m, s)$, but we sample from two distributions. The 
first distribution reflects the probability for two agents who are directly connected or separated by one individual; we set a higher mean for this distribution because of the greater likelihood of transfer, $N(0.700,0.100)$. The second distribution has a slightly lower mean, $N(0.350,0.100)$, because it reflects the probability of transfer between agents who are separated by two or more individuals, which is less likely. Although selecting from the same distribution for both cases did not change the pattern of results, ${ }^{1}$ drawing from two different probability distributions provides greater fidelity to prior findings and our theory.

\section{Social Distance and Knowledge Transformation}

We operationalize knowledge transformation as a function of social network distance: path length between two agents (McPherson and Ranger-Moore 1991). We assume that increasing path length increases the probability of knowledge transformation at a decreasing rate. We also assume that the challenges to knowledge transfer arising from social distance do not increase much more when the solution's source and recipient are extremely distant from each other. Put differently, in our model, the likelihood of transformation increases when path length increases but not at a constant rate of increase. Hence,

$$
P\left(K_{i j}\right)=\sqrt{L_{i j}} \times \zeta
$$

where $P\left(K_{i j}\right)$ is the probability of knowledge transformation between agent $\mathrm{i}$ and $\mathrm{j} ; L_{i j}$ represents the geodesic path lengths between two agents in the network in which directly connected agents have a path length of 1 ; $\zeta$ is the base probability of knowledge transformation-that is, the probability of transformation between directly connected agents. For example, suppose agent $B$ agrees to share her solution with agent A. $\zeta$ is a constant set at 5 percent. We explore additional values in the following sensitivity analysis. If $\zeta$ equals 5 percent, the solution will have only a 95 percent probability of accurately copying each digit shared if $\mathrm{A}$ and $\mathrm{B}$ are directly connected. Suppose A and B are not directly connected but are separated by a certain network distance; as the network distance increases, the probability of knowledge transformation increases, respectively. Thus, if agent $A$ and agent $B$ are four steps away, agent $A$ will have only a 90 percent probability of accurately copying each digit of solution from B. Moreover, the path length is transformed with the square-root function, which indicates the decreasing rate of increased probability. Accordingly, the probability of knowledge transformation increases less when the two agents are socially distant than when they are socially proximate.

Another aspect of knowledge transformation is its implication for efficiency. In the case of perfect knowledge transfer, we assume the time that is needed to change a solution by experimenting is the same as the time needed to learn a solution from others. Yet, this assumption may not hold across all scenarios, especially when knowledge is communicated between socially distant organizational members and can be transformed. We operationalized the effect of knowledge transformation on efficiency by incorporating the ratio between the time needed to learn one bit of solution (exploitation) and the time needed to experiment on one's own 
(exploring). This ratio represents the relative ease of learning and transforming existing certainties compared to experimenting with novel possibilities. We model the ratio as a function of path length between the source and the recipient of a solution. We also assume a nonlinear effect that path length is transformed with the square-root function, which indicates the decreasing rate of the decreased exploitation efficiency. Hence,

$$
R\left(K_{i j} / E_{i}\right)=\sqrt{L_{i j}} \times \gamma
$$

where $R\left(K_{i j} / E_{i}\right)$ is the ratio of agent $\mathrm{i}$, capturing the time needed to acquire one digit of solution from agent $\mathrm{j}$ in comparison to the time needed to experiment; $L_{i j}$ represents the geodesic path lengths between two agents in the network in which directly connected agents have a path length of $1 ; \gamma$ is the base difficulty of learning from others-that is, the potential time needed for transfer between directly connected agents in comparison to experimentation. $\gamma$ is a constant set to 0.050 . We explore additional values in the following sensitivity analysis. Put in an organizational context, the ratio is highly contingent upon how supportive the organization is towards knowledge transfer versus experimentation. The more supportive the organization is toward experimentation on one's own, the less effort required for experimentation and the higher the base difficulty $\gamma$ would be, suggesting a decreased efficiency of acquiring a solution from others compared to experimenting on one's own.

\section{Social Network Structures}

Variations in network structures have been found to influence organizational performance and innovation (Fang et al. 2010; Tortoriello et al. 2012). Because our models of knowledge transfer and knowledge transformation both hinge on social distance, we also varied the total social network distance or average path length (APL). We focus on the networks' APL in our analysis, given APL relevance to our theory (e.g., Lazer and Friedman 2007; Mason and Watts 2012). APL is the mean number of steps along the shortest distance between all member pairs (Lazer and Friedman 2007; Mason and Watts 2012). Information takes more time and is more likely to become distorted as it moves through networks with long APL (Goel, Watts, and Goldstein 2012). To this end, the networks were reconstructed by making a series of "degree-preserving random rewirings" (Mason and Watts 2012). These changes preserved the total number of connections for each agent while varying the overall configuration of the social network and its APL.

\section{Learning Efficiency and Effectiveness}

As noted earlier, for each experiment we examine two system-level outcomes that are common to organizational learning research: efficiency and effectiveness (Lazer and Friedman 2007; March 1991). The computational models reach convergence when agents can no longer improve their performance and all the agents have 
solutions that perform equally well. This shared solution represents the final solution to the organizational problem. We measure the efficiency and effectiveness after the model converges. For each model, we capture the simulated time needed to converge on the solution. Lower values reflect that the model quickly converged on one shared solution. To aid in interpretation, we reverse coded time to reflect efficiency and scaled it between 0 and 1 . As such, higher efficiency indicates less time spent to reach convergence.

Each NK problem has an optimal solution. In the NK model, individual score is a function of both $\mathrm{N}$ and $\mathrm{K}$. System effectiveness is the average of all agents' final scores; in most of the cases, all the agents share the same final solution. We normalized the model's final score against the theoretical maximum score. We also applied an exponential function to transform the distribution. This transformation makes the change in effectiveness easier to detect while preserving the ranked order of agents' performance (Lazer and Friedman 2007).

\section{Organizational Scenarios}

We construct three organizational scenarios to reflect different but common organizational learning conditions. In the first organizational scenario, we examine the most commonly studied form of learning: learning through social networks (Borgatti and Cross 2003; Fang et al. 2010; Hansen 1999, 2002; Lazer and Friedman 2007). In the second organizational scenario, we investigate a setting in which the organizational members can learn via a public repository. As previously noted, organizations are increasingly adopting public repository technologies such as expertise directories and documentation systems in an attempt to overcome unequal access to knowledge and accelerate learning (Hwang et al. 2015; Levine and Prietula 2012). In the third organizational scenario, we combine both social network and public repository learning to simultaneously capture the effect of both means of learning.

\section{Experiment 1: Learning via Social Networks}

Social networks play a critical role in knowledge transfer and organizational learning. Factors that have been found to affect knowledge transfer include the strength of the relationship (Hansen 1999), mutual third-party connections (Reagans and McEvily 2003; Tortoriello et al. 2012), and the structure of the surrounding relationships (Burt 2004).

When organizational members learn through social networks, members are made aware of the expertise of others either through direct connections or word-ofmouth communications. Connections between organizational members provide members with relevant knowledge about each other's expertise (Borgatti and Cross 2003). As we noted earlier, when members must depend on their social contacts to pursue a superior solution, their search tends to be overly local (Levinthal and March 1993). Knowledge transfer is more likely when members share a direct relationship or have a third member in common (Reagans and McEvily 2003; Tortoriello et al. 2012). Therefore, in the learning via social network experiment, we 
limit the search for superior solutions to members directly connected to the focal member or to those who are one connection apart from her. In other words, the agent will search among her direct connections to find a solution that outperforms her solution; if she cannot find a superior solution among the directly connected agents, she will next search solutions among her connections' connections.

\section{Experiment 2: Learning via Public Repositories}

The purpose of public repositories is to disseminate information to all members of the organization. Because solutions to complex problems can be difficult to document, organizations often provide public repositories in the form of expertise directories that permit organizational members to immediately locate experts with superior solutions (Ding et al. 2010; Kane and Alavi 2007; Levine and Prietula 2012). Public repositories, as such, facilitate organization-wide communication by connecting members to distant experts, which in turn can overcome unequal access to existing knowledge and aid knowledge transfer.

In this experiment, a list of the experts in the organization is publicly shared with all of the agents and updated dynamically. We define experts as those whose solutions score within the top 15 percent of all solutions present in the system. In other words, the list of experts is not static but can change according to the experts' fluctuations in performance. Agents rely on the repository to identify experts, and their search is not restricted to local connections.

\section{Experiment 3: Learning via Both Social Network and Public Repository}

In practice, most organizations that implement a public repository learning system also have an extant social network. To address this common occurrence, we also explore the combination of learning via both social networks and public repositories. In such organizations, members can access solutions via those with whom they are socially proximate through the social network and via the public information repository. Of note, however, research suggests that, when public repositories are in place, organizational members are reluctant to use them. Commonly, organization members continue to rely exclusively on their social networks to learn, even when a public repository is available (Hwang et al. 2015). Thus, members will prefer to rely on socially proximate others for help; however, when socially proximate help is not available, members will turn to public repositories and learn from socially distant others.

When both forms of learning are available, members can access both socially proximate and distant members with superior solutions. We apply a "strategic persistence" decision rule by which agents use social network learning or public repository learning, as explained in the subsequent subsection. Specifically, if an agent's seeking help from socially proximate members leads to an improved solution, she will continue to use only social network learning. Once the social network learning no longer leads to improved solutions, she will seek experts in the public repositories, and vice versa. $\mathrm{x}$ 


\section{Simulation Results}

It is important to note that the benefits of knowledge transformation are contingent on the complexity of the problem. As noted earlier, increasing the absolute value of $N$ increases the problem complexity, and, in addition, increasing the relative size of $K$ to $N$ also increases the problem complexity. Smaller $K$ to $N$ ratios indicate there is little interdependence among the $N$ units, and the problem is relatively simple, whereas, when the ratios are high, any unit of $N$ is highly dependent on other parts of the solution and changing any part of the solution fundamentally changes the solution's performance. In the case in which $K$ is small relative to $N$, reproducing a good solution is not challenging, and, as such, the value of knowledge transformation in particular and learning in general is less beneficial for such simple problems. Alternatively, when $K$ is very large relative to $N$ and any part of a given solution is highly dependent on other parts of the solution, changing any part of the solution would fundamentally change its performance. In essence, improvements to such interdependent problems are found almost at random, and members cannot incrementally improve the solution; thus, there is little benefit to learning from others. Consequently, our model applies to problems that have an intermediate level of interdependence and that are most common to organizations. For these types of problems, learning from others is particularly advantageous (Sorensen et al. 2006), and, in turn, knowledge transformation will most likely lead to performance gains. We present the results for models in which $K$ is half of $N$. We also examine and discuss the effect of varying $K$ in the sensitivity analysis section that follows.

We ran the simulations with $(N=30, K=15)$ and $(N=30, K=16) 100$ times each, with 50 simulated agents and both network and mixed information under 13 unique network configurations. ${ }^{2}$ We first present the results that assume perfect knowledge transfer and then present the results that assume knowledge transformation for each of the three organizational scenarios. Tables 1 and 2 present the summary of model assumptions.

The results for models based on knowledge transfer and knowledge transformation are plotted in Figure 1. The upper plot in Figure 1 shows the efficiency outcomes for the system, and the lower plot is the system effectiveness. Assuming only knowledge transfer, learning via public repositories is the most efficient system of the three, and learning via social networks is the most effective. An ANOVA analysis shows that the differences between the three systems are significant $(p<$ 0.001). Furthermore, when we assume perfect transfer, the mixed systems appear to realize the benefits of both means of learning; mixed learning systems are almost as efficient as public repositories and only moderately less effective than learning via the social network.

When we account for knowledge transformation in models, the comparative outcomes of public repositories and social network learning are reversed. The upper plot of Figure 1 shows that learning via public repositories, as compared with social network and mixed learning, is the least efficient system $(p<0.001)$. In addition, the mixed learning systems parallel the efficiency of social network learning. The mixed learning systems do not exhibit a significant increase in either efficiency ( $p=$ $0.220)$ or effectiveness compared with social network learning $(p=0.608)$. 
Table 1: Summary of the knowledge transfer model.

\begin{tabular}{|c|c|c|}
\hline Independent Factors & & \\
\hline Information Seeking & Social Network, Public & 3 \\
\hline & Repositories, Mixed & \\
\hline NK Complexity $(\mathrm{N}, \mathrm{K})$ & $(30,15),(30,16)$ & 2 \\
\hline Network & 13 network configura- & 13 \\
\hline & tions (Short to Long & \\
\hline & APL) & \\
\hline & Total & $3 * 2 * 13=78$ \\
\hline & Replications & 100 \\
\hline & Total Runs & 7,800 \\
\hline Constants & & \\
\hline Persistence Strategy & & $70 \%$ Persistent, 30\% Alternate \\
\hline Number of Agents & & 50 \\
\hline Memory Length & & 10 \\
\hline Solution Attempts & & $\mathrm{N}$ \\
\hline
\end{tabular}

\section{Outcomes}

Efficiency

Effectiveness

Variables Explored

Persistence Strategy
The reverse-coded value of the mean of all agents' time spent problem solving (the number of problem-solving attempts before system convergence) Maximum final score from all agents' solutions

\section{Constants}

Number of Agents

$\{70 \%$ Persistent, 30\% Alternate $\},\{30 \%$ Persistent, $70 \%$ Alternate $\}$

In the knowledge transfer model, increasing APL in social network learning systems delays agent convergence to a solution. In public repositories, by contrast, efficiency is relatively unaffected by APL increase. Mixed information systems behave similarly to public repositories. Figure 2 (the lower plot) shows the effects of increasing network APL on system efficiency when organizational learning cost is taken into account in the model. For this knowledge transformation model, increases in the network APL continue to slow efficiency for the social network learning systems. Because knowledge transformation is taken into account in this model, public repository learning systems become sensitive to APL. Knowledge transformation significantly reduces system efficiency in public repository learning systems, and an increase in the network APL exacerbates this reduction. The mixed information systems, respectively, no longer maintain stable efficiency as the APL increases, as they did in the knowledge transfer model; instead, efficiency declines. With the inclusion of learning costs, the mixed information systems' efficiency becomes sensitive to changes in the network structure as the public repository learning systems' does.

In the knowledge transfer model, public repository learning promotes knowledge homogeneity, because marginal solutions diffuse rapidly. With knowledge homogeneity, agents can no longer learn from other agents; thus, they stop innovating and thereby reduce the likelihood of discovering the global optima. By 
Table 2: Summary of the knowledge transformation model.

\begin{tabular}{|c|c|}
\hline \multicolumn{2}{|l|}{ Independent Factors } \\
\hline Information Seeking & $\begin{array}{l}\text { Social Network, Public } \\
\text { Repositories, Mixed }\end{array}$ \\
\hline NK Complexity $(\mathrm{N}, \mathrm{K})$ & $(30,15),(30,16)$ \\
\hline \multirow[t]{4}{*}{ Factors } & $\begin{array}{l}13 \text { network configura- } \\
\text { tions (Short to Long } \\
\text { APL) }\end{array}$ \\
\hline & $3 * 2 * 13=78$ \\
\hline & Replications \\
\hline & Total Runs \\
\hline \multicolumn{2}{|c|}{ Constants (All from Knowledge Transformation Model, plus) } \\
\hline Problem Complexity & $\mathrm{K}=3,6,9,15$, and 19 \\
\hline Persistence Strategy & $30 \%, 40 \%, 50 \%, 60 \%, 70 \%$ Persistent \\
\hline $\begin{array}{l}\text { Likelihood of Sharing } \\
\text { Info }\end{array}$ & Path Length $\leq 2:(0.700,0.100)$, Path Length $>2:(0.350,0.100)$ \\
\hline Transfer Time & $\gamma *$ SQRT(Path Length) unit per bit transferred \\
\hline $\begin{array}{l}\text { Probability of Knowl- } \\
\text { edge Transformation }\end{array}$ & $\zeta *$ SQRT(Path Length) \\
\hline Time to Experiment & 1 unit per bit flipped \\
\hline \multicolumn{2}{|l|}{ Outcomes } \\
\hline Efficiency & $\begin{array}{l}\text { The reverse-coded value of the mean of all agents' time spent problem solving } \\
\text { (the number of problem-solving attempts before system convergence) }\end{array}$ \\
\hline Effectiveness & Maximum final score from all agents' solutions \\
\hline \multicolumn{2}{|l|}{ Variables Explored } \\
\hline $\begin{array}{l}\text { Organizational Support } \\
\text { for Experimentation } \\
\text { (Transfer Time vs. Time } \\
\text { to Experiment) }\end{array}$ & $\begin{array}{l}\text { Change "Time to Experiment" in comparison with knowledge transfer time; } \\
\text { the higher the organizational support, the lower time to solve }\end{array}$ \\
\hline $\begin{array}{l}\text { Likelihood of } \\
\text { Knowledge Transfer }\end{array}$ & $\begin{array}{l}\text { Tested models where the likelihood of sharing information does not vary } \\
\text { with path length }\end{array}$ \\
\hline $\begin{array}{l}\text { Probability of Knowl- } \\
\text { edge Transformation }\end{array}$ & Varied base probability between $3 \%$ to $15 \%$ \\
\hline
\end{tabular}

contrast, agents in social network learning systems can learn only from agents with whom they share a connection; hence, agents can become isolated by performance islands where they cannot find superior solutions. Nevertheless, these performance islands preserve knowledge heterogeneity and prevent the system from premature convergence on suboptimal solutions. Knowledge transformation, which we operationalized as the inclusion of learning costs in the forms of interpersonal challenges, reverses these results. Assuming knowledge can be transformed, public repository systems incur more losses in efficiency than social network learning systems incur, while simultaneously stemming knowledge heterogeneity from the very beginning. 
Finally, when social barriers are accounted for, mixed information systems, rather than providing the benefits of both public repository and social network learning systems, only improve short-term effectiveness compared to social network learning systems.

\section{Sensitivity Analysis}

We conducted a series of sensitivity analyses to confirm the robustness of the model and test our assumptions. The analyses included the probability of knowledge transformation (Equation 1), the agent's strategies for learning, and organizational factors such as the organization's size (the total number of agents). Our results were robust to variations in simulation assumptions, as we discuss below.

\section{The Probability of Knowledge Transformation}

In Equation 1, we set $\zeta$, the "base" probability of knowledge transformation, to 5 percent. To examine the effect of varying the probability of knowledge transformation, we varied $\zeta$ from 3 percent to 15 percent. Results with three milestone points (3 percent, 5 percent, and 9 percent) are presented in Figure 3. Varying $\zeta$, as would be expected, introduces more variance into the system, which, in turn, slows down the system's convergence at a decreasing rate. Thus, the effects indicate that network distance is stronger when the base probability of transformation increases. When $\zeta$ is lower than 3 percent, the model behaves similarly to the "transfer" model.

\section{The Effect of Strategic Persistence Assumption}

Strategic persistence is a risk-averse behavior in which the agents tend not to change their strategy if it proved successful in the prior round. In general, the systems in which agents are less risk averse and attempt to alter their strategy tend to achieve higher effectiveness. To ensure that our results were stable, we ran two variations in the knowledge transfer model. In the first, we applied the strategic persistence assumption to 70 percent of the agents, with the remaining 30 percent alternating between solving and seeking. In the second, we ran the model with 70 percent of the agents alternating between solving and seeking and the remaining 30 percent maintaining strategic persistence. We found our results to be robust to both proportions of strategic persistence agents in the knowledge transfer model, as indicated in Figure 4. In the knowledge transformation model (where $\zeta$ was set to 5 percent), we ran five variations to check the robustness of our results. We applied the strategic persistence assumption to 30 percent, 40 percent, 50 percent, 60 percent, and 70 percent of the agents. When the percentage of agents that persist with their successful strategy was assumed to be lower than 30 percent, that is, 70 percent of the agents would alter their previously successful strategy, we found that learning via public repositories can no longer yield effectiveness advantages, as indicated in Figure 5. When the majority of the agents in the system were assumed to be risk seeking and persisting with unsuccessful strategy in the knowledge 

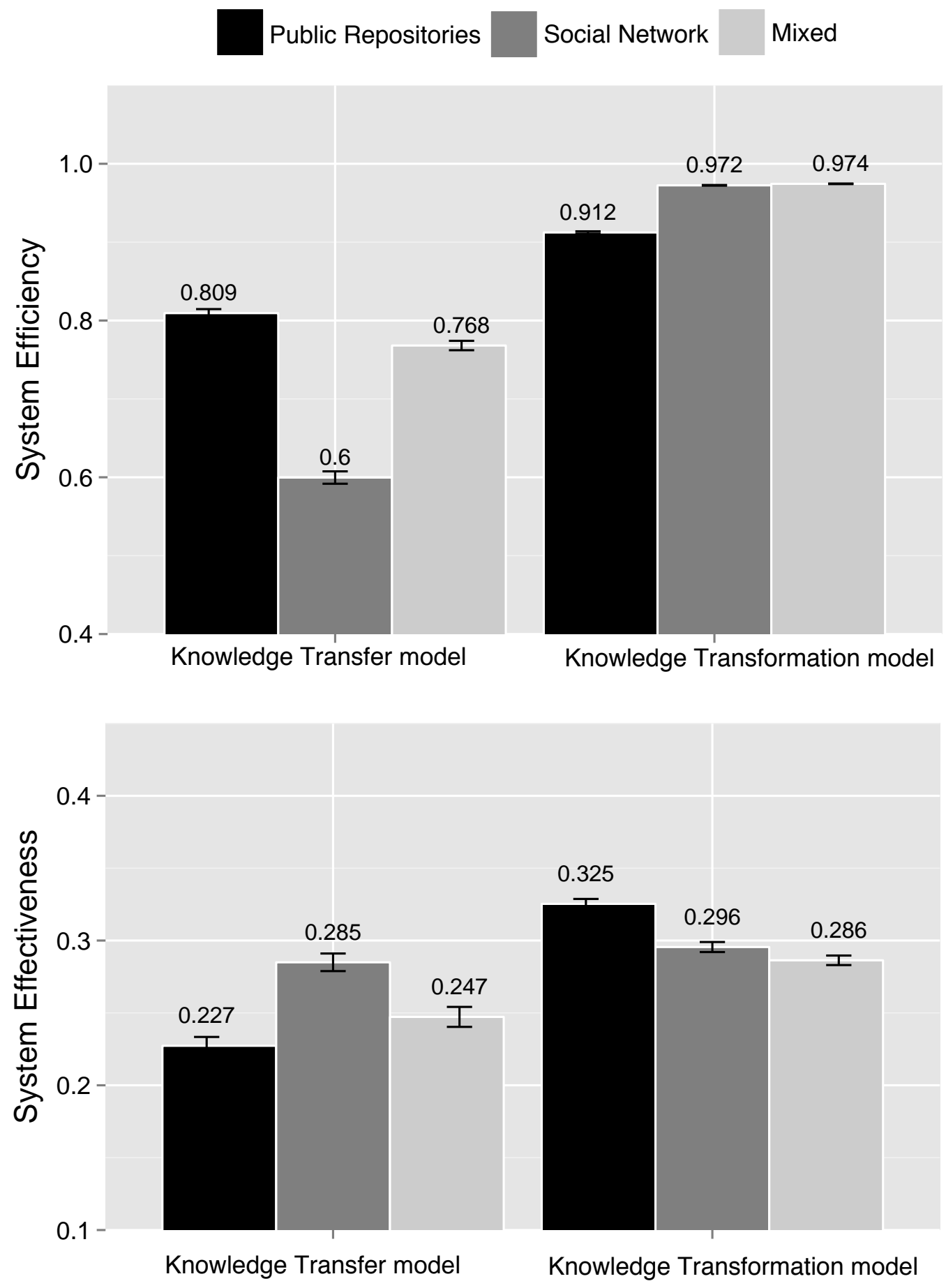

Figure 1: Effects of learning via public repositories, learning via social networks, and mixed information on system efficiency and effectiveness (the knowledge transfer model versus the knowledge transformation model). Maximum efficiency and effectiveness in both models are normalized to 1 . Results are based on 50 simulated agents solving 2 problems (100 times each) with 13 unique network configurations. 


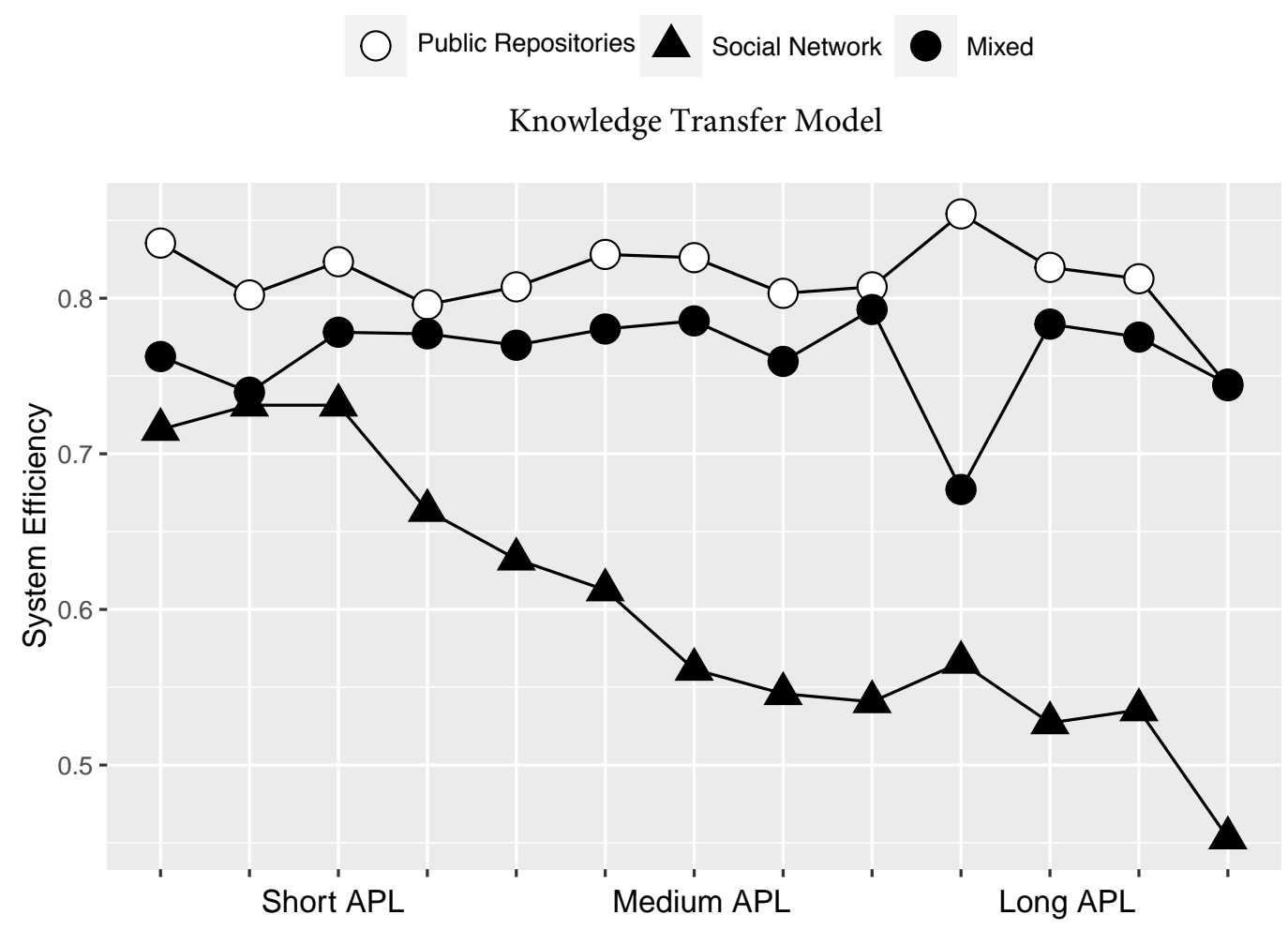

Knowledge Transformation Model

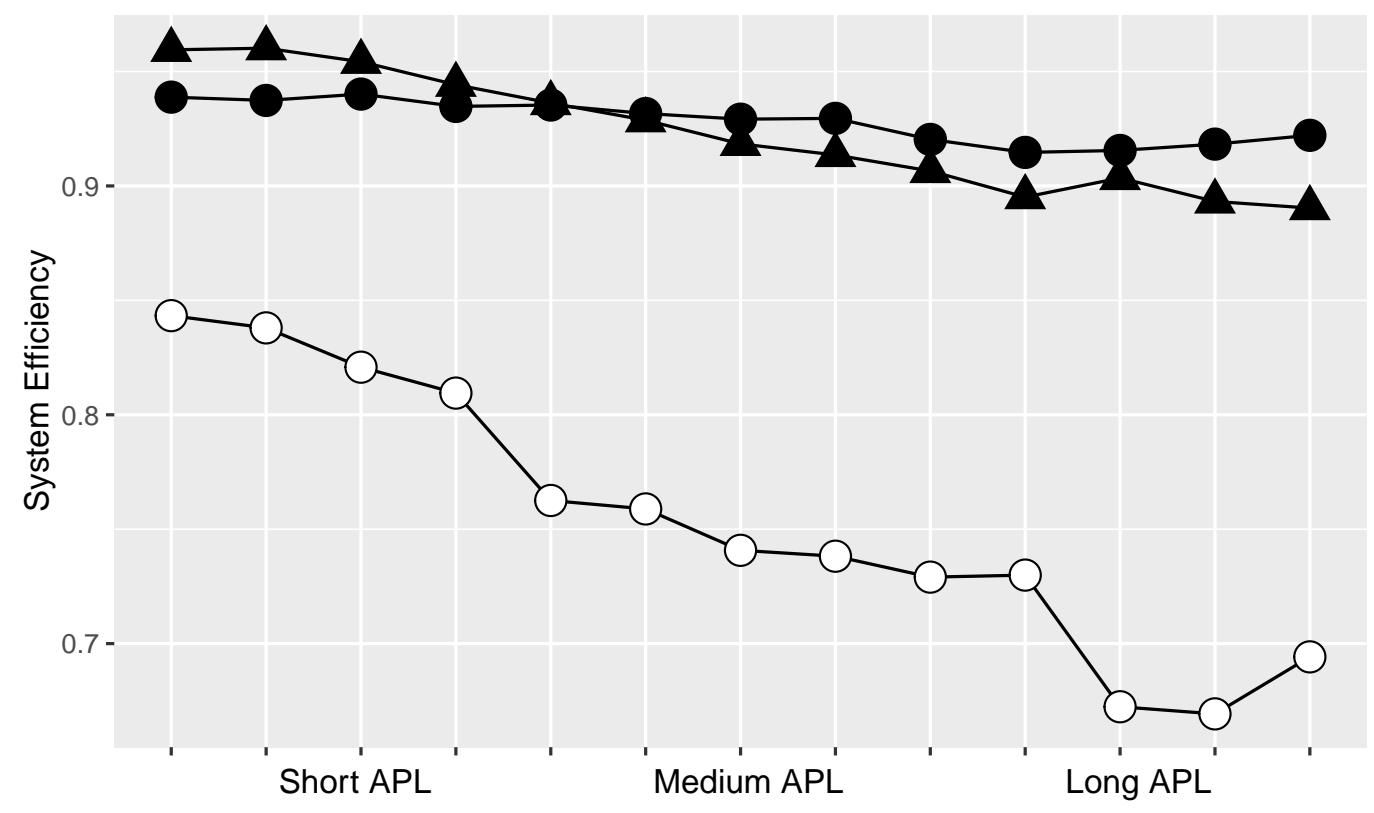

Figure 2: Effects of network APLs for information systems on efficiency (upper plot: the knowledge transfer model; lower plot: the knowledge transformation model). 


\section{Public Repositories Social Network Mixed}
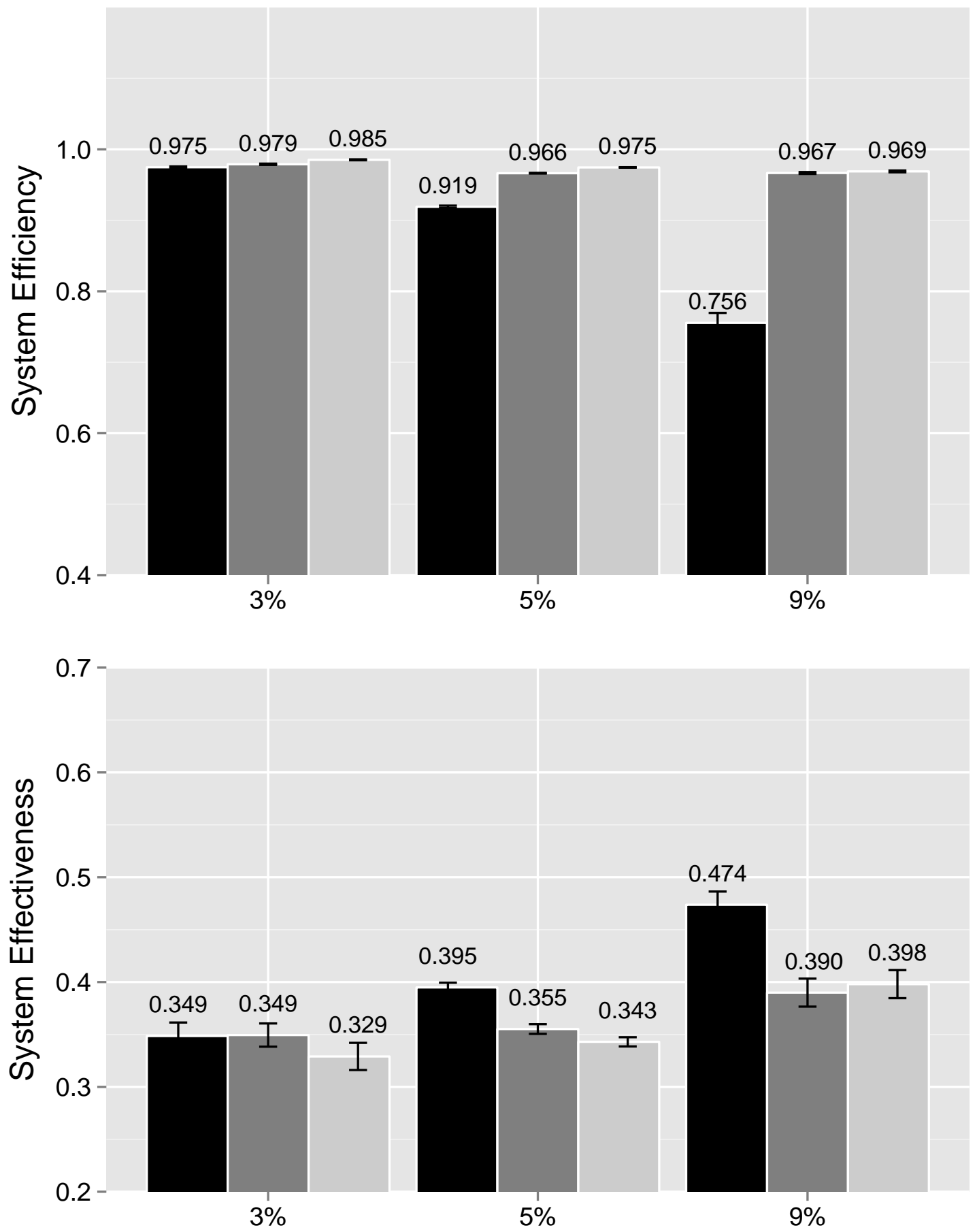

Figure 3: Effects of public repositories, social network, and mixed information on system efficiency and effectiveness (with a varied probability of knowledge transformation) in the knowledge transformation model. The maximum efficiency and effectiveness in both models are normalized to 1 . 
transformation model, learning via social network leads to higher effectiveness because it encourages mainly experimentation.

\section{The Effect of Organizational Support for Individual Learning}

We varied the ratio of time to experimentation and sharing to examine the effects by varying $\gamma$ in Equation 2 (setting $\gamma$ to 0.050 and 0.100, respectively); the results are shown in Figure 6. As the organization becomes more supportive towards experimentation (as is reflected by a higher value of $\gamma$ ), public repository systems become less efficient as compared to either the social network or mixed learning systems. Nonetheless, the pattern of the results of organizational learning, as reported in the main article, remained robust.

\section{The Effect of Problem Complexity}

We varied the problem complexity, $K$, and examined the effects of knowledge transfer and knowledge transformation by setting $K$ to 3, 6, 9, 15, and 19 while holding $N$ constant at 30 . We did not simulate beyond K equal to 19 , as the problem became so complex that solving it would be due more to random chance than to learning. The results are presented in Figure 7. As shown, the pattern of results stabilizes when K equals only 6 and persists up to 19 . Thus, our results are consistent for a range of problems with intermediate levels of complexity.

\section{Discussion and Conclusion}

In the knowledge transfer model, in which solutions are perfectly transferred from one agent to another, learning via public repositories promotes knowledge homogeneity, in that all of the agents quickly learn from a small set of experts. This increased knowledge homogeneity leads the system to converge quickly on a solution, which reduces the likelihood of discovering the global optima. By contrast, agents in social network learning systems have access only to socially proximate experts; hence, they are stranded in performance islands, where they may not be able to reach experts. These performance islands preserve knowledge heterogeneity and prevent the system from premature convergence on suboptimal solutions. When we account for knowledge transformation, these results are reversed. In the knowledge transformation models, public repository learning systems are less efficient than learning via social network learning systems, while simultaneously stemming knowledge homogeneity. In other words, when we account for transformation when learning from socially distant others, rather than reducing knowledge heterogeneity, public repositories increase it.

We extend traditional organizational learning models of knowledge transfer to account for the effects of social network distance through knowledge transformation and show how accounting for knowledge transformation can reverse the expected results of classical models of knowledge transfer (e.g., Fang et al. 2010; March 1991; Schilling and Fang 2014). In particular, we focus on three systems common to organizational learning: social networks, from which members learn 

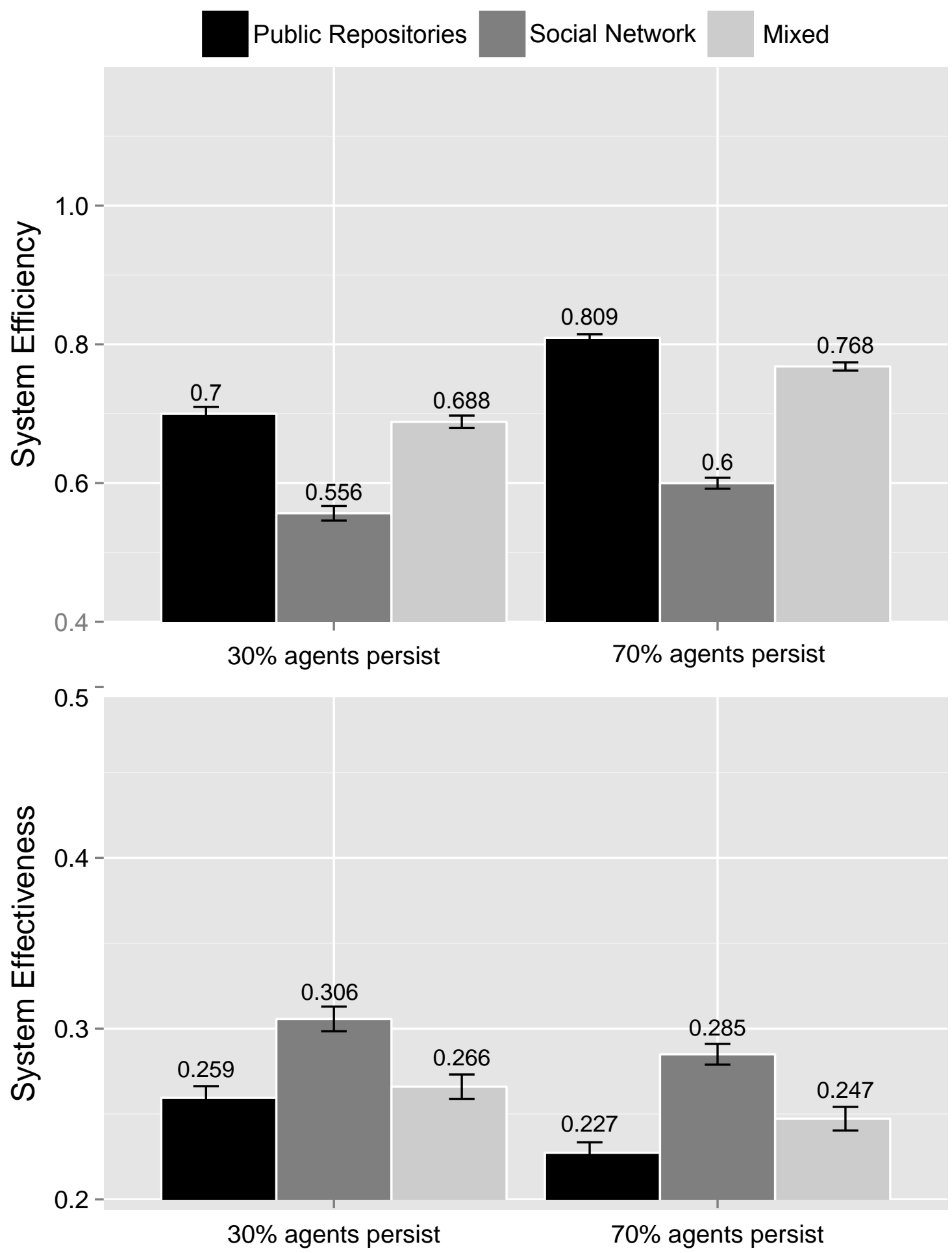

Figure 4: Effects of public repositories, social network, and mixed information on system efficiency and effectiveness (70 percent agents versus 30 percent agents persist with successful strategy) in the knowledge transfer model. The maximum efficiency and effectiveness in both models are normalized to 1. 


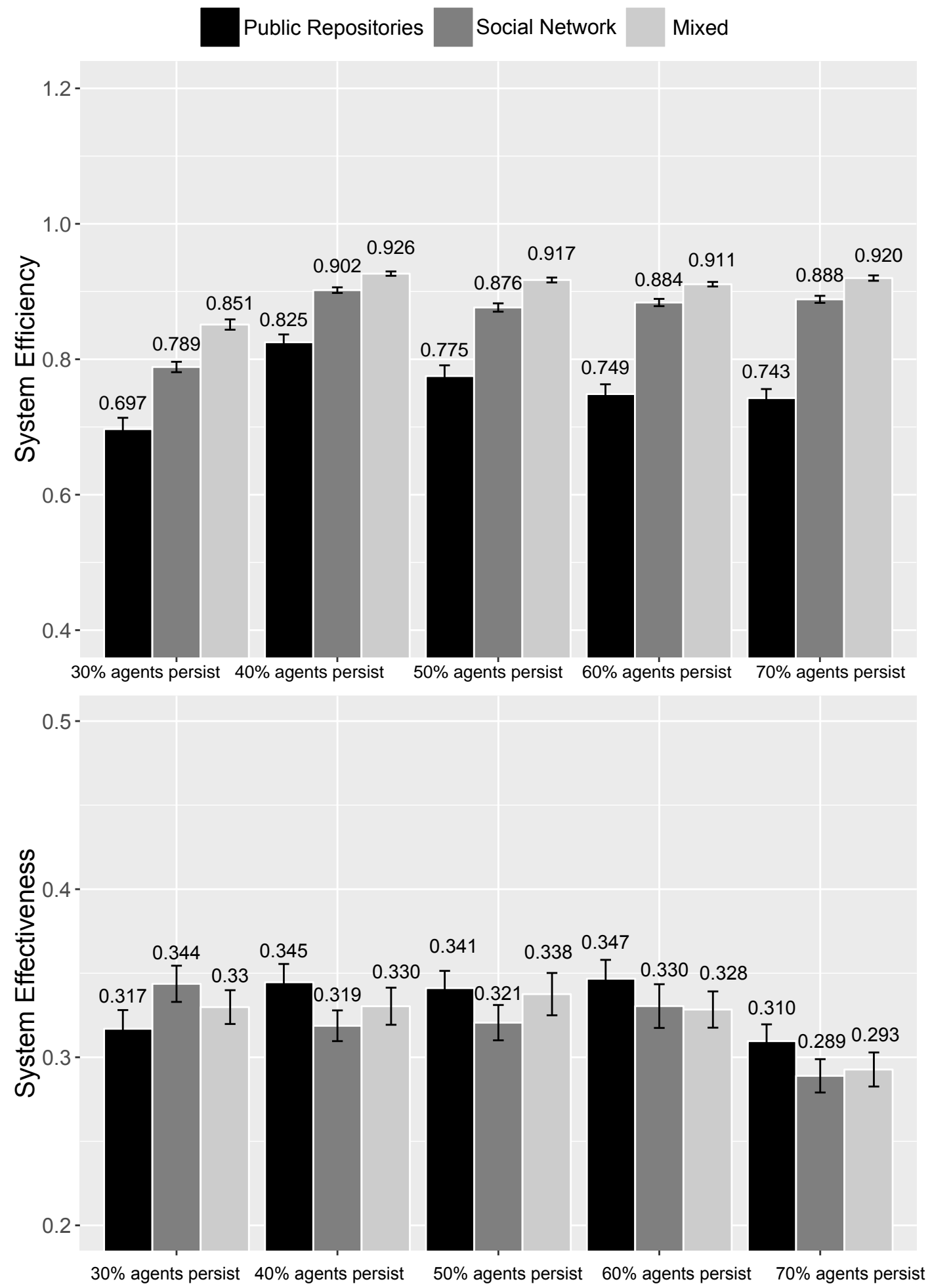

Figure 5: Effects of public repositories, social network, and mixed information on system efficiency and effectiveness ( 30 percent $~ 70$ percent agents persist with successful strategy) in the knowledge transformation model. The maximum efficiency and effectiveness in both models are normalized to 1 . 

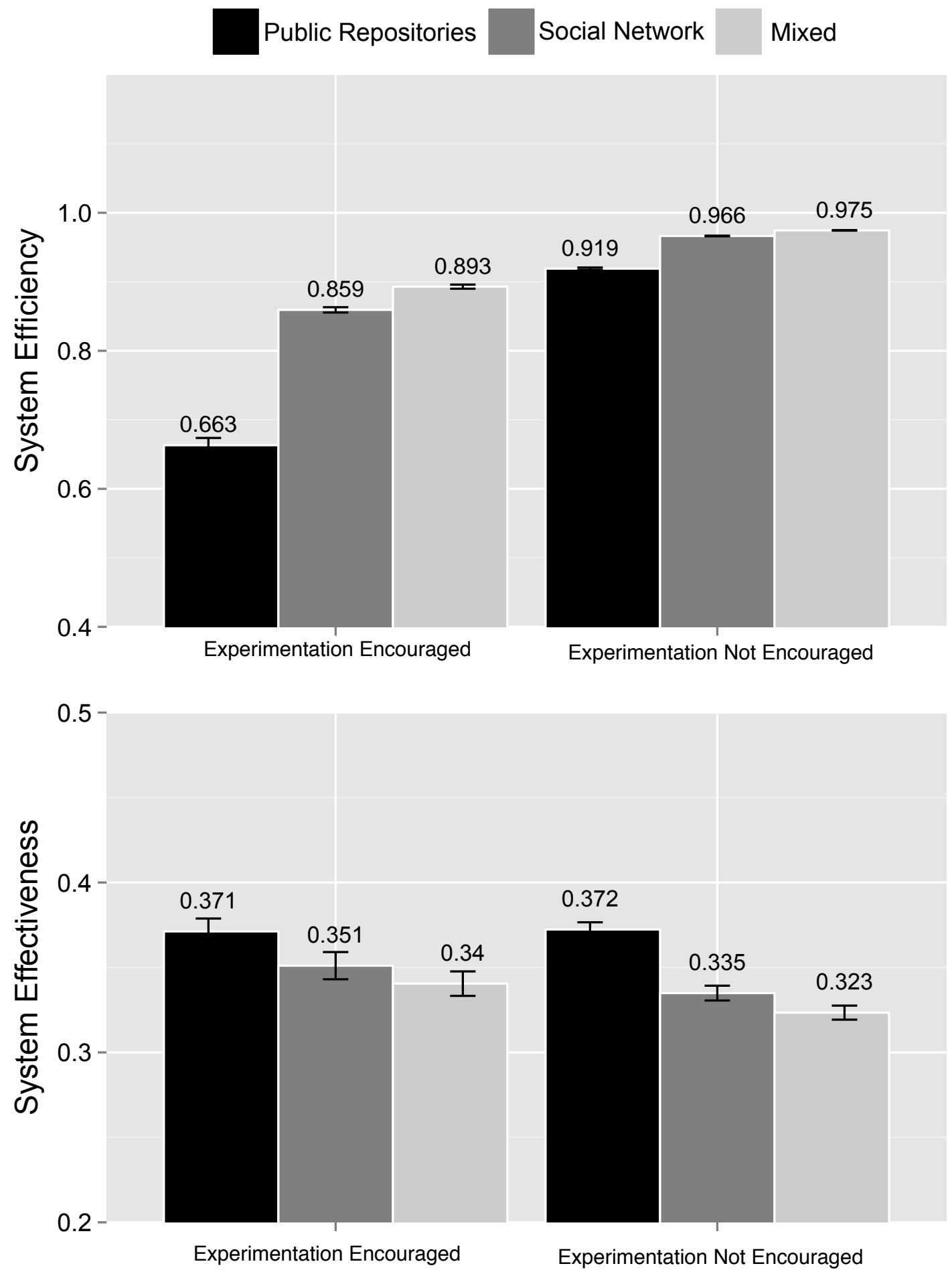

Figure 6: Effects of public repositories, social network, and mixed information on system efficiency and effectiveness in the knowledge transformation models when individual experimentation is encouraged versus when it is not encouraged. The maximum efficiency and effectiveness in both models are normalized to 1. 


\section{Social Network Mixed}

$1.2-$


Figure 7: Effects of public repositories, social network, and mixed information on system efficiency and effectiveness (with a varied problem complexity $K$ in the NK model) in the knowledge transformation models. The maximum efficiency and effectiveness in both models are normalized to 1. 
only from those with whom they share a social connection; public repositories, from which members can learn from any top performers in the organization; and mixed systems, from which members can learn either from social contacts or from top performers. Prior theories uniformly suggest that certain contingencies that accelerate the diffusion of a solution to members, such as public repository systems, will lead to premature convergence and undermine organizational effectiveness (March 1991; Fang et al. 2010; Schilling and Fang 2014).

We argue that, rather than accelerating convergence to a suboptimal solution, public repository systems such as knowledge management systems can actually be less efficient but more effective in discovering solutions than social network learning systems. Despite the challenges to efficiency, the learning over social network distance fostered by public repository systems benefits the organization by preserving solution heterogeneity through the transformation of the knowledge. Just as in ecological settings in which random mutation introduces variety into a species, knowledge can also mutate. We thus conclude that, by neglecting the social network distance in knowledge sharing, traditional models of knowledge transfer run the risks of overestimating a system's efficiency in diffusing solutions and underestimating a system's effectiveness for innovating solutions.

Our findings are particularly relevant to recent research on the development of organizational-level transactive memory systems (Lewis, Lange, and Gillis 2005). Transactive memory system research suggests that when groups leverage existing knowledge and develop an understanding of "who knows what," they can better use existing knowledge and achieve greater levels of performance. The majority of this research has been conducted with small groups, and little is known about the upper limits of group size for transactive memory systems (Argote and Ingram 2000). And yet, the rationale for the implementation of many knowledge management systems is that they extend to all employees the knowledge of "who knows what" or of the experts beyond their proximate relations. Our results for mixed information systems suggest that there might be limits to transactive memory system implementation via the introduction of certain technologies. In other words, an organization's competitive advantage depends not on what the organization knows but on the extent to which employees can learn from each other.

Although we focus on intra-organizational knowledge transfer and transformation, the mechanisms would readily apply to interorganizational networks. In fact, Posen, Lee, and Yi (2013) investigate imitation amongst firms and find that imperfect imitation can lead to improved outcomes; that is, the outcomes for the copier surpass the outcomes of the firm being copied. Drawing on the Carnegie School tradition (Cyert and March 1963), Posen et al. (2013) assume that firms cannot correctly identify their industry leaders and that firms cannot perfectly copy the leader. Our theory suggests that firms would rely on copying their social networks but switch to copying industry leaders when outcomes no longer improved. In addition, we contend that as the social distance between the industry leader and the firm seeking to copy increases, so, too, does the likelihood that the imitation will be imperfect. Stuart and Podolny (1996) propose a similar model of social network distance for firm knowledge; however, in contrast to organizational members, as firms become more similar, they are at greater risk of becoming competitors. Thus, 
factors such as competitive pressures should be considered when considering the effect of social network distance on interfirm learning.

Building on recent advances in the understanding of organizational structures and performance (e.g., Schilling and Fang 2014), our work incorporates how organizational learning is affected by social network distance. In addition to social network distance, other antecedences of "knowledge transformation" exist, such as deliberately withholding or misrepresenting information (Fang et al. 2014). We speculate that social network distance would moderate these less collaborative forms of knowledge transformation and that it would be easier to alter or withhold information if individuals had few shared contacts with whom to corroborate information. Future studies might test the moderating effect of social network distance on these types of behaviors.

Our results suggest that social network structures moderate the relationship between social network and public repository learning; however, our models assume stable network structures. Current work on the effect of technology-based knowledge management systems on networks does not suggest that knowledge management systems can alter social network structures over time. For example, Hwang et al. (2015) show that, despite the implementation of an organizationwide knowledge management system, organizational members are still confined by geographic and social boundaries. Thus, knowledge management systems are unlikely to encourage connections among socially distant members. Nonetheless, future research should examine the effect of organizational information systems with dynamic social networks. We would anticipate that tie formation is more likely if organizational members successfully learn from a socially distant expert.

\section{Notes}

1 We also ran simulations drawing from the same distribution, $\mathrm{N}(0.700,0.100)$, and the patterns of results remain robust.

2 The simulation model was implemented in NetLogo and built on the NK and smallworld models in the available in NetLogo public library (Watts and Gilbert 2014).

\section{References}

Argote, L., and P. Ingram. 2000. "Knowledge Transfer: A Basis for Competitive Advantage in Firms." Organizational Behavior and Human Decision Processes. 82(1): 150-169. http: //dx.doi.org/10.1006/obhd.2000.2893.

Bechky, B. A. 2003. "Sharing Meaning Across Communities: The Transformation of Understanding on a Production Floor." Organization Science. 14(3): 312-330. http: //dx.doi.org/10.1287/orsc.14.3.312.15162.

Blau, P. M. 1977. “A Macrosocial Theory of Social Structure." American Journal of Sociology. 83(1): 26-54. http://dx.doi.org/10.1086/226505.

Borgatti, S. P., and R. Cross. 2003. "A Relational View of Information Seeking and Learning in Social Networks." Management Science. 49(4): 432-445. http://dx.doi.org/10.1287/ mnsc.49.4.432.14428. 
Burt, R. S. 2004. "Structural Holes and Good Ideas." American Journal of Sociology. 110(2): 349-399. http://dx.doi.org/10.1086/421787.

Carlile, P. R. 2002. "A Pragmatic View of Knowledge and Boundaries: Boundary Objects in New Product Development." Organization Science. 13(4): 442-455. http://dx.doi .org/ 10.1287/orsc. 13.4.442.2953.

Cyert, R. M., and J. G. March. 1963/1992. A Behavioral Theory of the Firm. 2nd ed. Prentice Hall, Englewood Cliffs, NJ.

Dougherty, D. 1992. "A Practice-Centered Model of Organizational Renewal Through Product Innovation." Strategic Management Journal. 13: 77-92. http://dx . doi .org/10.1002/ smj . 4250131007.

Fang, C., J. H. Kim, and F. J. Milliken. 2014. “When Bad News is Sugarcoated: Information Distortion, Organizational Search and the Behavioral Theory of the Firm." Strategic Management Journal. 35(8): 1186-1201. http://dx.doi .org/10.1002/smj . 2146.

Fang, C., J. Lee, and M. A. Schilling. 2010. "Balancing Exploration and Exploitation Through Structural Design: The Isolation of Subgroups and Organizational Learning." Organization Science. 21(3): 625-642. http://dx.doi.org/10.1287/orsc.1090.0468.

Fleming, L., S. Mingo, and D. Chen. 2007. “Collaborative Brokerage, Generative Creativity, and Creative Success." Administrative Science Quarterly. 52(3): 443-475. http: //dx.doi. org/10.2189/asqu. 52.3.443.

Goel, S., D. J. Watts, and D. G. Goldstein. 2012. "The Structure of Online Diffusion Networks." Proceedings of the 13th ACM Conference on Electronic Commerce. 1(212): 623-638. http: //dx.doi.org/10.1145/2229012.2229058.

Haas, M. R., and M. T. Hansen. 2007. “Different Knowledge, Different Benefits: Toward A Productivity Perspective on Knowledge Sharing in Organizations." Strategic Management Journal. 28: 1133-1153. http://dx.doi.org/10.1002/smj.631.

Hansen, M. T. 1999. “The Search-Transfer Problem: The Role of Weak Ties in Sharing Knowledge Across Organization Subunits." Administrative Science Quarterly. 44(1): 82111. http://dx.doi.org/10.2307/2667032.

Hargadon, A., and R. Sutton. 1997. "Technology Brokering and Innovation in a Product Development Firm." Administrative Science Quarterly. 42(4): 716-749. http://dx.doi. org/10.2307/2393655.

Hwang, E. H., P. V. Singh, and L. Argote. 2015. "Knowledge Sharing in Online Communities: Learning to Cross Geographic and Hierarchical Boundaries." Organization Science. 26(6): 1593-1611. http://dx.doi.org/10.1287/orsc.2015.1009.

Kane, G. C., and M. Alavi. 2007. "Information Technology and Organizational Learning: An Investigation of Exploration and Exploitation Processes." Organization Science. 18(5): 796-812. http://dx.doi.org/10.1287/orsc.1070.0286.

Kleinbaum, A. M., T. E. Stuart, and M. L. Tushman. 2013. “Discretion Within Constraint: Homophily and Structure in a Formal Organization." Organization Science. 24(5): 13161357. http://dx.doi.org/10.1287/orsc.1120.0804.

Lazer, D., and A. Friedman. 2007. "The Network Structure of Exploration and Exploitation." Administrative Science Quarterly. 52: 667-694. http://dx.doi.org/10.2189/asqu .52.4. 667.

Levine, S., and M. Prietula. 2012. “How Knowledge Transfer Impacts Performance: A Multilevel Model of Benefits and Liabilities." Organization Science. 23(6): 1748-1766. http://dx.doi.org/10.1287/orsc.1110.0697. 
Levinthal, D. A. 1997. "Adaptation on Rugged Landscapes." Management Science. 43(7): 934-950. http://dx.doi.org/10.1287/mnsc.43.7.934.

Levinthal, D. A., and J. G. March. 1993. “The Myopia of Learning." Strategic Management Journal. 14(Special Issue: Organizations, Decision Making and Strategy): 95-112.

Lewis, K., D. Lange, and L. Gillis. 2005. “Transactive Memory Systems, Learning, and Learning Transfer." Organization Science. 16(6): 581-598. http://dx.doi.org/10.1287/ orsc. 1050.0143 .

Lingo, E., and S. O'Mahony. 2010. "Nexus Work: Brokerage on Creative Projects." Administrative Science Quarterly. 55: 47-81. http://dx.doi .org/10.2189/asqu .2010.55.1.47.

March, J. G. 1991. “Exploration and Exploitation in Organizational Learning." Organization Science. 2(1): 71-87. http://dx.doi.org/10.1287/orsc.2.1.71.

Mason, W., and D. J. Watts. 2012. "Collaborative Learning in Networks." Proceedings of the National Academy of Sciences. 109(3): 764-769. http://dx.doi.org/10.1073/pnas . 1110069108.

McPherson, J. M., and J. R. Ranger-Moore. 1991. “Evolution on a Dancing Landscape: Organizations and Networks in Dynamic Blau Space." Social Forces. 70(1): 19-42. http: //dx.doi.org/10.2307/2580060.

McPherson, M. 2004. "A Blau Space Primer: Prolegomenon to an Ecology of Affiliation." Industrial and Corporate Change. 13(1): 263-280. http://dx.doi.org/10.1093/icc/13.1. 263.

Miller, K. D., M. Zhao, and R. J. Calantone. 2006. “Adding Interpersonal Learning and Tacit Knowledge to March's Exploration-Exploitation Model." Academy of Management Journal. 49(4): 709-722. http://dx.doi.org/10.5465/AMJ . 2006. 22083027.

Obstfeld, D. 2005. "Social Networks, the Tertius Iungens Orientation, and Involvement in Innovation." Administrative Science Quarterly. 50(1): 100-130. http://dx.doi.org/10 . 2189/asqu.2005.50.1.100.

Posen, H. E., J. Lee, and S. Yi. 2013. "The Power of Imperfect Imitation." Strategic Management Journal. 34(2): 149-164. http://dx.doi.org/10.1002/smj . 2007.

Reagans, R., and B. McEvily. 2003. “Network Structure and Knowledge Transfer: The Effects of Cohesion and Range." Administrative Science Quarterly. 48(2): 240-267. http: //dx.doi.org/10.2307/3556658.

Rodan, S., and C. Galunic. 2004. "More than Network Structure: How Knowledge Heterogeneity Influences Managerial Performance and Innovativeness." Strategic Management Journal. 25(6): 541-562. http://dx.doi .org/10.1002/smj . 398.

Schilling, M. A., and C. Fang. 2014. "When Hubs Forget, Lie, and Play Favorites: Interpersonal Network Structure, Information Distortion, and Organizational Learning." Strategic Management Journal. 35(7): 974-994. http://dx.doi.org/10.1002/smj . 2142.

Singh, J., M. T. Hansen, and J. M. Podolny. 2010. “The World Is Not Small for Everyone: Inequity in Searching for Knowledge in Organizations." Management Science. 56(9): 1415-1438. http://dx.doi.org/10.1287/mnsc.1100.1201.

Sorenson, O., J. W. Rivkin, and L. Fleming. 2006. "Complexity, Networks and Knowledge Flow." Research Policy. 35(7): 994-1017. http://dx.doi .org/10.1016/j .respol . 2006. 05.002 .

Stuart, T. E., and J. M. Podolny. 1996. "Local Search and the Evolution of Technological Capabilities." Strategic Management Journal. 17: 21-38. http://dx.doi.org/10.1002/ smj . 4250171004. 
Szulanski, G. 1996. "Impediments to the Transfer of Best Practice within the Firm." Strategic Management Journal. 17(1): 27-43. http://dx.doi.org/10.1002/smj . 4250171105.

Szulanski, G., R. Cappetta, and R. J. Jensen. 2004. "When and How Trustworthiness Matters: Knowledge Transfer and the Moderating Effect of Causal Ambiguity." Organization Science. 15(5): 600-613. http://dx.doi.org/10.1287/orsc.1040.0096.

Tortoriello, M., R. Reagans, and B. McEvily. 2012. “Bridging the Knowledge Gap: The Influence of Strong Ties, Network Cohesion, and Network Range on the Transfer of Knowledge Between Organizational Units." Organization Science. 23(4): 1024-1039. http://dx.doi.org/10.1287/orsc.1110.0688.

Tortoriello, M., F. Taube, and S. Moebus. 2014. "Lost in Transition: Knowledge Acquisition and Knowledge Loss in Interpersonal Exchanges." Academy of Management Best Paper Proceedings. OMT Division. http://dx. doi.org/10.2139/ssrn. 2387347.

Watts, C., and N. Gilbert. 2014. Simulating Innovation: Computer-Based Tools for Rethinking Innovation. Edward Elgar Pub, Cheltenham, UK. http://dx.doi.org/10.4337/ 9781783472536.

Winter, S. G., G. Szulanski, D. Ringov, and R. J. Jensen. 2012. “Reproducing Knowledge: Inaccurate Replication and Failure in Franchise Organizations." Organization Science. 23(3): 672-685. http://dx.doi.org/10.1287/orsc.1110.0663.

Acknowledgements: We are particularly grateful to Linda Argote for her extensive comments and suggestions. We also wish to thank all of the participants in the Strategy and Management Seminar Series at the Tuck School of Business, the Organizational Behavior and Theory Seminar at the Tepper School of Business, and the Carnegie School's Organizational Learning Conference for the helpful suggestions and critiques. Please direct correspondence to Brandy Aven, Tepper School of Business, Carnegie Mellon University.

Brandy Aven: Tepper School of Business, Carnegie Mellon University.

E-mail: aven@cmu.edu.

Evelyn Ying Zhang: Tepper School of Business, Carnegie Mellon University. E-mail: yingzhang@cmu.edu. 